\title{
Scott Barry Kaufman, Transcend: The New Science of Self-Actualization, TarcherPerigee, New York 2020, pp. 432
}

Freshly released Transcend: The New Science of Self-Actualization by an American humanistic psychologist, Scott Barry Kaufman, proclaims to present "a new hierarchy of human needs for the twenty-first century” (Kaufman, 2020, p. xxvi). This might appear to be an ambitious challenge, if not a bold undertaking, especially after a few decades of dominance by Abraham Maslow's classic pyramid. But Kaufman is certainly well-equipped for the challenge. An experienced researcher and scholar, teaching at Columbia University, NYU, and the University of Pennsylvania, he has published numerous works on creativity (including Wired to Create: Unraveling the Mysteries of the Creative Mind with Carolyn Gregoire), intelligence and human potential. Therefore, it would be worth examining what contribution his new book has made to the existing theories on human needs.

However, the first question that might arise is: do we really need a new hierarchy of needs for the twenty-first century, other than just the one with the lowest level for "wi-fi" added to the Maslow's pyramid, as is humorously illustrated in the graphic, circulating through the Internet? Kaufman strongly urges that we do and that "Maslow's pyramid" is not in fact Maslow's, which one might find an interesting discovery. The author cites sources proving that the iconic pyramid became so hyper-popular due to some management consultant who created it for business purposes - but Maslow himself never actually drew a pyramid to represent his ideas. Kaufman argues that such a depiction of a hierarchy of needs is a "gross misinterpretation of Maslow's theory, as well as the spirit of Maslow's overall

1 Doctoral School of Social Sciences at the University of Łódź, Poland. E-MAIL: agnieszka.janiszewska.szczepanik@edu.uni.lodz.pl ORCID: 0000-0001-6745-5040 
body of work" (p. xxvi) and a "parody” of this great thinker's rich intellectual contributions, including ideas on self-actualization (p. xxix).

Why is the pyramid so inadequate? Kaufman's point is that it fails to represent the processual aspect of human growth and creates a false impression that life is about climbing levels, like - to use the author's metaphor that is repeated throughout the publication - in the video game. Kaufman obviously does not deny that there is a certain hierarchy of human needs, but a particular need that is fulfilled at the given moment does not just disappear to never be felt by an individual again but must be harmoniously integrated within the process of further growth. Moreover, the regression to lower needs is always possible and even necessary because human development is not a constant one-way upward movement but - as Maslow stated - "a two-steps-forward, one-step-back dynamic" (as cited in Kaufman, 2020, p. xxviii). Also - what seems to be an important observation - humans can also grow as a result of being able to endure deprivations and not only due to harmonious gratification of each and every need in the "correct" order.

The vital aspect, however, is that Kaufman does not just stop with criticism of the triangular stage-like representation of Maslow's theory but he proposes a new metaphor, which is that of a "sailboat". The author creates a new model for the representation of a theory of human needs, arguing that it is a far more adequate substitute for the old - apparently overly simplistic - one. Let us, therefore, attempt to briefly present and evaluate Kaufman's updated version of the theory of a human hierarchy of needs.

Replacing the pyramid with a sailboat is not only about changing the depiction. The main modification lies in the arrangement and choice of the very needs. As we remember the five levels of the traditional pyramid, "built" - moving from the bottom to the top - from physiological needs, safety, love and belonging, esteem, and self-actualization, now we will have a boat "assembled" from safety, connection and self-esteem, which together form "security". The top part of the boat is the "sail", composed of exploration, love, and purpose - three of which are parts of "growth". Self-actualization has been replaced by transcendence (or - more precisely - the self-actualization need is partially included in "growth", which finally leads to transcendence), which is located above the sail.

Certainly, this model is much more complex than the stage-like pyramid, which probably makes it less likely to "conquer the world" as the old one did. But is it actually - as Kaufman apparently intends for the readers to believe - a more adequate representation of a human needs hierarchy? It must be acknowledged how extensive and meticulous research or analysis of research Kaufman has done on the issue of human needs. The reader becomes acquainted with abundant data 
and its explanation regarding the nature of the needs and effects of their gratification or deprivation in terms of human brain function and general psychological and physiological wellbeing. The author effectively shows how psychological processes are intertwined with the neurochemistry of the body and how stress crushes general growth and inhibits creativity. He is not only well equipped with facts and figures but also provides illustrative examples (e.g., "If you've spent the entire previous night lying awake worrying about an ambiguous blood test result, it might be hard to compose a symphony the next day”; Kaufman, 2020, p. 11). It is also a commendable - especially from the eastern European perspective - aspect of Kaufman's study that he does not limit himself to the American-centered perspective on research from this area of interest but acknowledges a very broad and global body of work, mentioning contributions of other scholars, e.g., Polish psychiatrist Kazimierz Dąbrowski with his prominent theory of "positive disintegration” (p. 104).

However, some characteristics of a "sailboat" might stir controversy. For instance, the author equates hunger with attachment and also makes a distinction between the need for attachment and connection (providing ample data and clarifications for why attachment would be such a fundamental need and how it is different from connection). It is not within the scope of this review to argue for or against such modifications of the traditional Maslow's “order” of needs, however, they might - and probably deserve it, as Kaufman has put a lot of effort in the presentation of his theory - encounter constructive criticism and feedback from other experts of human needs theory and scholars of other related disciplines.

Given the above, one might see that the book is quite an in-depth analysis of human needs in general, which makes the title - or at least the subtitle The New Science of Self-Actualization - rather misleading. "The new science of human needs" would possibly give a better clue to the actual contents, which is not focused solely on self-actualization but rather gradually reveals the process of approaching the state of the titular "transcendence".

The notion of transcendence is a highly interesting one - Kaufman has made an impressive attempt to continue Maslow's studies that Maslow did not manage to finish during his lifetime. As Kaufman informs, in the final years of his career, Maslow started to work on the theory of transcendence, which was intended to replace the self-actualization theory. The chapter on transcendence is a wonderful review of ideas Maslow not always managed to publish but - according to sources Kaufman has dug into - clearly intended to convey. It is not only an analysis of Maslow's works as Kaufman goes many steps further with the clear aim of formulating a scientifically-based (but also taking into consideration some exist- 
ing philosophical and spiritual concepts) theory of what is "above” - if for a brief moment we would go back to the "good old pyramid" - self-actualization.

In general, it must be appreciated how extensively Kaufman studied Maslow's original writings - articles, books, diaries, and all the other unpublished papers - and how successfully he has blended pieces of Maslow's body of work into his updated human needs theory. Apart from the unpublished theory of transcendence, Kaufman touches on more interesting phenomena Maslow introduced - e.g., the "Jonah complex". Described by Maslow as an important factor inhibiting self-actualization (Maslow, 1971), this concept has been rarely mentioned in any scientific paper since then. As Maslow's theories have sometimes been criticized for being more philosophical than scientific, Kaufman strives to make them more accurate and scientifically-based. For instance, what Maslow used to call "continued freshness of appreciation” (of creative people; Kaufman, 2020, p. 111), Kaufman specifies it into neurochemically well-explained "reduced latent inhibition” (p. 110). Further, building on Maslow's legacy, Kaufman proposes his own (or along with co-workers) innovative concepts, e.g., a theory of "the Light Triad” (p. 122).

The question that remains is: who would the publication's intended readers be? It seems three main types of recipients can be distinguished. First and most obvious would be experts in positive and humanistic psychology and related disciplines, scholars specifically interested in theories of human needs as well as educators wishing to apply the latest knowledge on how human potential could be best realized into their practice. Kaufman's focus on human growth and general development of talents, creative skills, and interests make it highly likely that, e.g., admirers of ideas of the recently deceased, great creativity expert and proponent of revolutionizing the education system, Ken Robinson, would also find some inspiration in Kaufman's studies and concepts.

The second group - which will most probably overlap the first one - are scholars specifically interested in Maslow's theories, continuators of this great thinker's body of work, and exponents of his ideas. Why one should separately distinguish such a target audience is because Kaufman not only outlines Maslow's theories but is also interested in him as, so to say, a "fellow human being". The author diligently traces his “dear friend's” (as he calls Maslow, following Maslow's idea that a friend is someone to whom one has great affection and respect, regardless of the actual relationship or even the lack of it; Kaufman, 2020, p. xviii) career and life history, hence readers keen about exploring Maslow's biography might find a thing or two of interest. For instance, it might be exciting to learn about the roots of Maslow's interest in self-actualization which started as a developing admiration for his mentors, whom he was trying to "work out" by taking notes on their 
personality characteristics. He realized that these traits could be generalized and out of this conclusion his famous theory of self-actualization came into existence. The book covers numerous anecdotes on Maslow's course of scientific development (e.g., his crystallizing experiences) and sources of inspiration, which could be of value to readers curious about the background of the humanist psychology movement and the life of one of its leading representatives.

The last group - and this seems the most problematic aspect of the work - is the "general audience" interested in self-development. Kaufman states it very clearly that through his writing he intends to help his readers to "boldly and honestly face who you are head-on so that you can become the person you really want to become" (p. xx). And if such a bold goal has been set, it would be worth it to ask: how effectively was it accomplished?

First of all, the goal is quite blurry and exaggerated, as in the cases of numerous self-development manuals. Moreover, mixing the formal and data-packaged tone of scientific publication with the conversational and hyper-positive message style of a typical self-help book does not always go smoothly - and as one might find in the existing literature reviewing Kaufman's previous works, similar shortcomings have been observed regarding, e.g., Wired to Create: Unraveling the Mysteries of the Creative Mind (Kaufman's previous book, written together with Carolyn Gregoire, see: Sasin, 2018). The incoherent style is not such a profound problem as to be a reason for giving up reading the book, but it might happen that if the reader is an expert in the discussed field they will find self-help passages to be just an unnecessary distraction. The same applies to the opposite situation - if one wants Kaufman's book to serve as a classic manual of selfdevelopment, extensive scientific explanations might seem tortuous and overcomplicated.

Even though Transcend... seems to be more exhaustive in covering the undertaken issues than Wired to Create... did, there are still fragments in this publication that are quite disturbing due to not so graceful juggling between different styles of discourse. For instance, having spent many pages winding through in-depth analyses of modern scientific research on human needs, neurochemistry of the brain, etc., a surprised reader will "suddenly" be offered a piece of glossy magazine-like psych test, starting with: "You spend the evening at your partner's house...” (Kaufman, 2020, p. 20). Then there are two answers to choose from - without much explanation of the meaning of the result though. There are many tests/quizzes/scales through the publication that seem to have some value in terms of presenting what narcissism, secure attachment, dark triad, etc., are all about. Unfortunately, without much further clarification of the results, they can hardly 
help one in "becom[ing] the person you really want to become" (Kaufman, 2020, p. xx), as the above-mentioned author's intention states.

Surely - even if not having a tremendous cognitive or scientific value - providing real-life examples, exercises and psych tests, as Kaufman often does, might just be a useful technique to facilitate engagement and make the text more accessible to a wider audience, which has some value in itself and is understandable. However, there are much less admirable fragments, in which, for instance, the author gives the reader the following advice: "If your primary goal in life is to have power, money and status, that's fine, but you can probably stop reading this book right now. My advice would be to take close notes on the strategies of those who have an abundance of characteristics associated with grandiose narcissism. Individuals who have high levels of grandiose narcissism seem to find ways to get ahead and dominate, regardless of the costs to others" (Kaufman, 2020, pp. 7980 ). And that might come as a nasty surprise after the dominantly warm and allinclusive style of Kaufman's discourse, in which he repeatedly declares that there is always room for personal growth and no matter what the circumstances, one should pursue their goals, fulfil one's needs in a healthy manner and overcome obstacles with the final aim of experiencing transcendence. However, in the given example, Kaufman just seems to forget his general idea that growth is a process and - suddenly sounding quite elitist and a bit judgmental - decided to categorize his readers into groups that do or do not deserve to gain access to higher levels of human development, not to mention suggesting to self-diagnose narcissism basing only on the author's very general statements like "I like being the most popular person at a party” (p. 72).

There are some more oversimplifications and minor flaws in the author's reasoning that form fractures in the otherwise well-grounded in theory and research and logical narrative. For instance, a statement like "An often-overlooked growth purchase is therapy” (Kaufman, 2020, p. 48), might arise doubts as to its justification in the era of self-development and therapeutic interventions boom. To provide another example, in the author's question: "does self-actualization really have any relevance anymore in this cutthroat, competitive world we live in?”, a strain of unnecessary drama can be sensed as the argument that, in the past, self-actualization used to be more valued might be hard to defend. Kaufman contradicts himself in a fragment where he points out (quoting another writer, Ruth Whippman) that in modern society people have inverted Maslow's hierarchy, "placing self-actualization as a viable alternative to these [safety needs] fundamentals” (p. 7). Of course, one could probably argue well for both points of view (that there is not enough room for self-actualization or, on the contrary, that it supersedes other 
human needs) but in one publication of a single author, a consistent line of thought would be a clear asset.

Regardless of its shortcomings, for the most part, the publication is a highly successful narrative of ideas in humanistic psychology such as wellbeing, creativity, intelligence, and human potential. Kaufman makes a great contribution to reinstating Maslow's ideas and generally reigniting the spirit of the original humanistic psychology movement. Whether a "sailboat" is or is not a better framework for a human needs theory and constitutes a breakthrough in the field remains to be seen and is undoubtedly an issue worthy to be discussed further, as Kaufman has put a lot of effort into presenting his concept. All in all, Kaufman's eagerness to put forward an innovative and well-researched model, which substantially modifies what for a few decades has been believed to be obvious and invulnerable (due to the ever-presence of the iconic "pyramid"), should be appreciated as a clear sign of intellectual courage and creative approach to scientific activities.

\section{References}

Kaufman, S.B. (2020). Transcend: The New Science of Self-Actualization. New York: TarcherPerigee. (Kindle Paperwhite Version. Retrieved from: amazon.com)

Maslow, A. (1971). The Farther Reaches of Human Nature. New York: Penguin Group.

Sasin, M. (2018). [Review of the book Kreatywni. I masz pomysł na wszystko [Wired to Create: Unraveling the Mysteries of the Creative Mind], by S.B. Kaufman \& C. Gregoire]. Nauki o Wychowaniu. Studia Interdyscyplinarne [Educational Sciences: Interdisciplinary Studies], 7(2), pp. 252-255. 